Supporting information for

\title{
Transforming Sword into Knife: Persistent Phototoxicity Inhibition and Alternative Therapeutical Activation of Highly-Photosensitive Phytochlorin
}

Nuo Yu, Pu Qiu, Qian Ren, Mei Wen, Peng Geng, Daniel K. Macharia, Meifang Zhu, Zhigang Chen*

State Key Laboratory for Modification of Chemical Fibers and Polymer Materials, College of Materials Science and Engineering, Donghua University, Shanghai 201620, China.

Email: zgchen@dhu.edu.cn

\section{Experimental section}

Instruments. The morphology and elements of particels were characterized by using transmission electron microscopy (TEM, FEI Talos F200S) equipped with energy dispersive spectroscopy (EDS), and X-ray photoelectron spectroscopy (XPS, Escalab 250Xi). The photoproperties were recorded on UV-vis-NIR absorption spectrophotometer (Shimadzu UV1900) and fluorescence spectrophotometer (Jasco FP-6600). The Fourier transform infrared (FTIR) spectra were acquired from samples in $\mathrm{KBr}$ pellets using a spectrometer (Nicolet NEXUS670). The surface area was tested on an automated area and pore size analyzer (Autosorb-iQ). The particle size and Zeta potential were performed on a Malven Nano ZS analyzer. The thermogravimetric (TG) analysis was performed on a TGA8000 thermogravimetric analyzer. The NIR laser with the wavelength of $660 \mathrm{~nm}$ was purchased from Changchun New Industries Optoelectronics Tech. Co., Ltd. During irradiation, the temperature change of solutions was monitored by using an infrared camera (FLIR A300).

Density functional theory (DFT) calculations. The self-consistent periodic DFT calculations were carried out using the DMol3 code as implemented in the Materials Studio package. The electron exchange and correlation were described with B3LYP functional. The localized double-numerical quality basis set with a polarization d-function (DNP) was chosen to expand the wave functions. The core electrons of the metal atoms were treated using the effective core potential (ECP). 
Statistical Analysis. The data were expressed as the mean value \pm standard deviation (SD), and any statistical comparison between two groups was analyzed using the Student's two-tailed $t$ test. ${ }^{*} p<0.05$ (significant), ${ }^{* *} p<0.01$ (moderately significant), and $* * * p<0.001$ (highly significant).

\section{Supplementary figures}
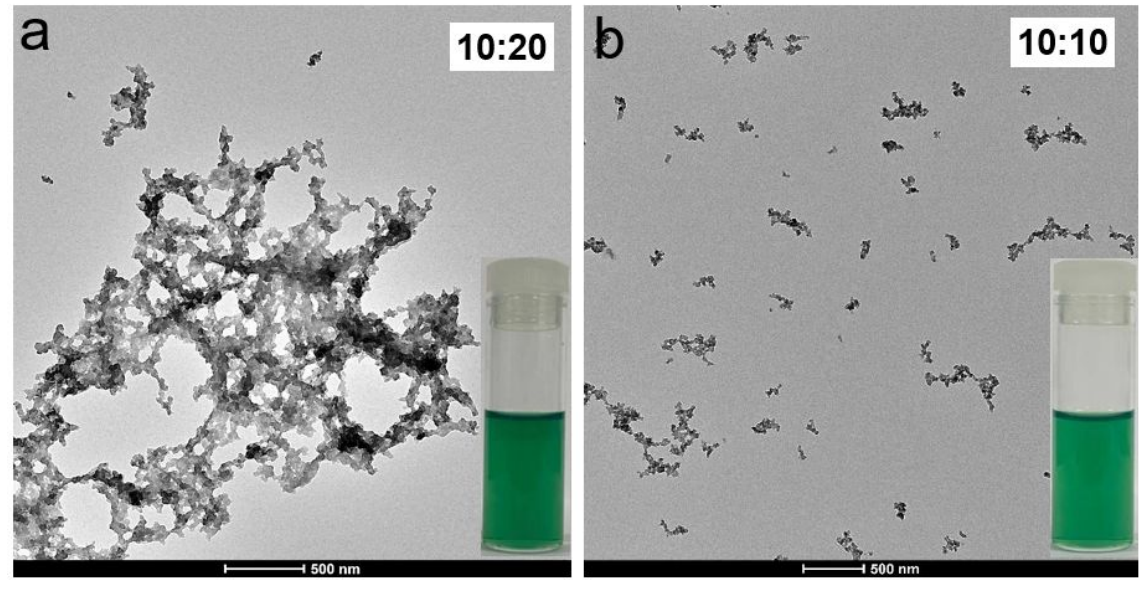

Figure S1. TEM image of frameworks obtained by using $\mathrm{CuCl}_{2} \cdot 3 \mathrm{H}_{2} \mathrm{O} / \mathrm{Ce} 6=20 \mathrm{mg} / 10 \mathrm{mg}$ and 10 $\mathrm{mg} / 10 \mathrm{mg}$. These samples are green in ethanol solution.

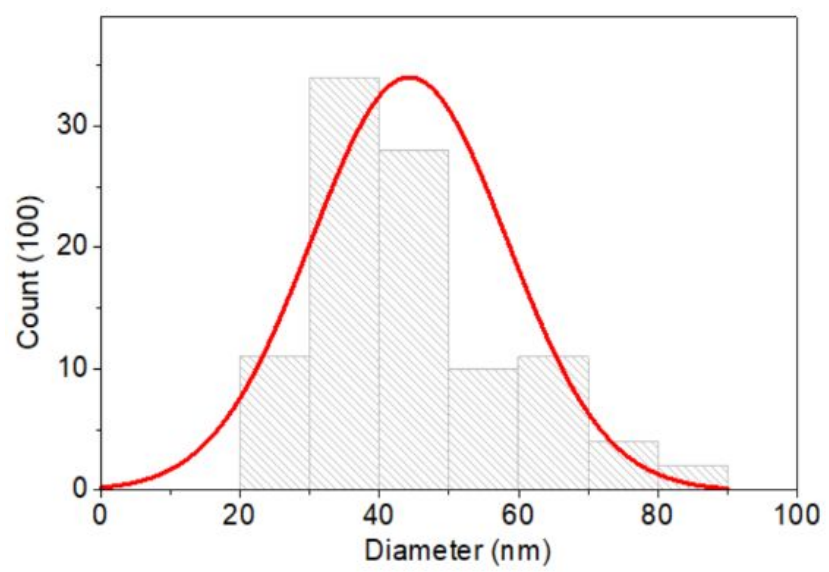

Figure $\mathrm{S} 2$. The size histogram of $\mathrm{nFs}$ by counting 100 particles. 

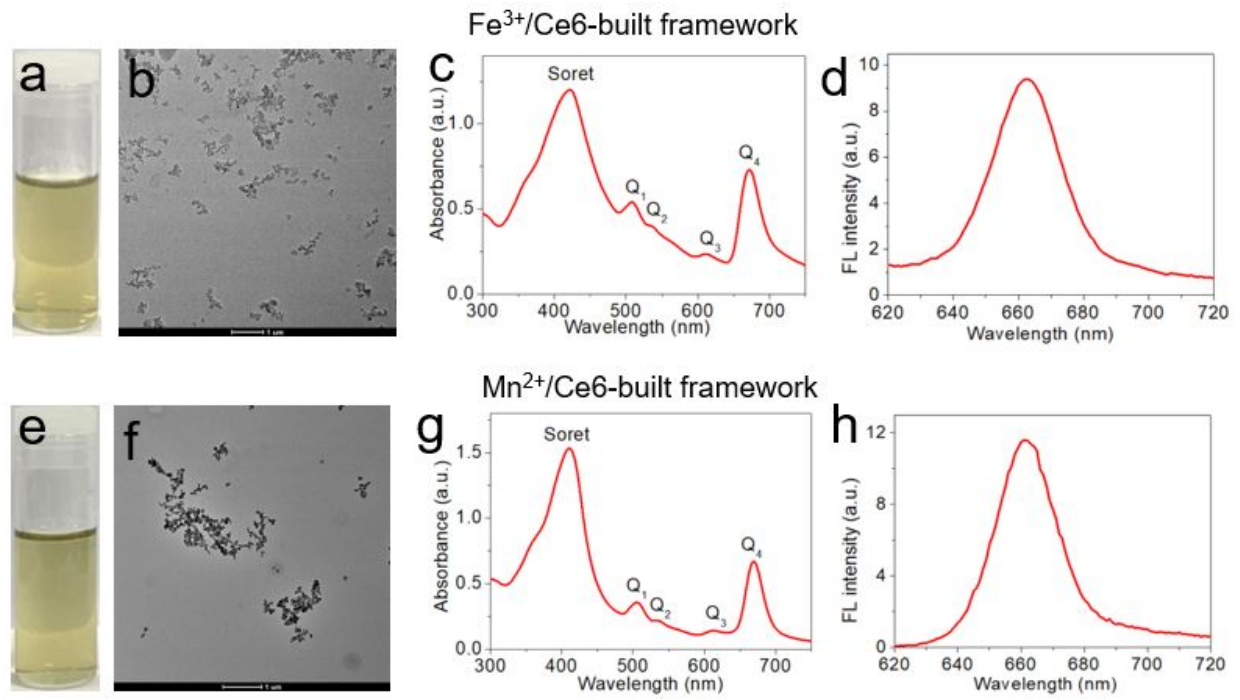

Figure S3. (a, e) Photographs, (b, f) TEM images, (c, g) UV-vis-NIR absorption spectra, and (d, h) Fluorescence spectra $(\mathrm{Ex}=400 \mathrm{~nm})$ of $\mathrm{Fe}^{3+} / \mathrm{Ce} 6-$ built and $\mathrm{Mn}^{2+} / \mathrm{Ce} 6$-built frameworks.

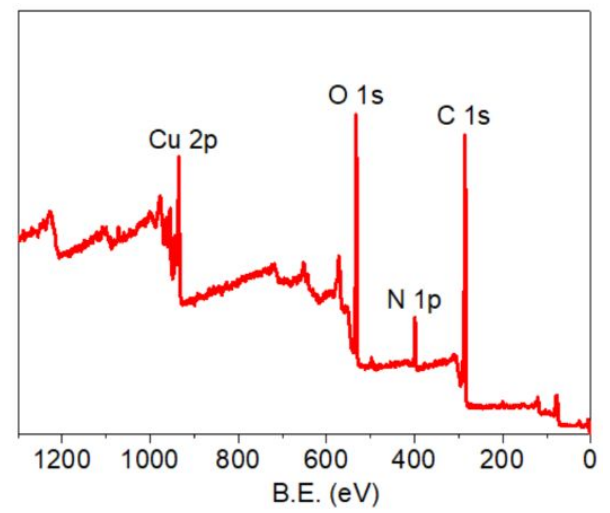

Figure S4. Survey XPS spectra of nFs powder with peaks of $\mathrm{Cu} 2 \mathrm{p}, \mathrm{O} 1 \mathrm{~s}, \mathrm{~N} 1 \mathrm{~s}$ and $\mathrm{C} 1 \mathrm{~s}$.

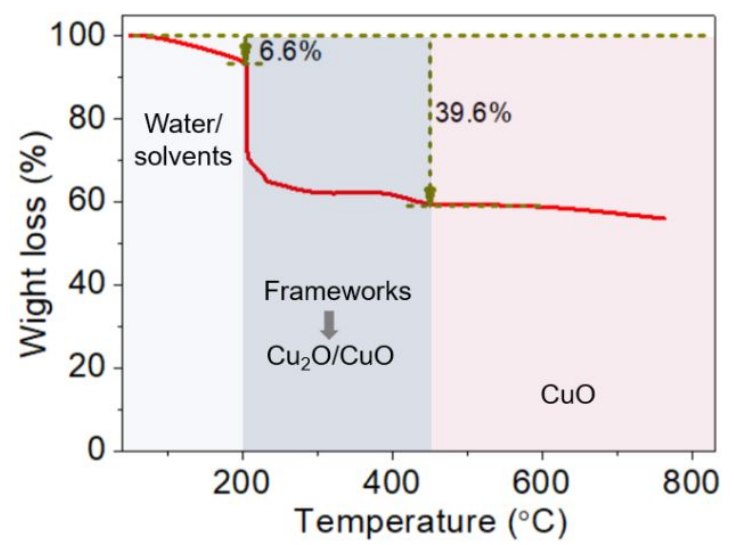

Figure S5. Thermogravimetric (TG) curve of $\mathrm{nFs}$ powder in the air. (1) The first stage $(6.6 \%)$ occurs at below $200{ }^{\circ} \mathrm{C}$, due to the removal of water and solvents; (2) the second stage ( $\left.40 \%\right)$ exhibits big weight loss at below $310^{\circ} \mathrm{C}$ and then slight weight loss ended around $450{ }^{\circ} \mathrm{C}$, which is attributed to the transformation from nFs into $\mathrm{Cu}_{2} \mathrm{O} / \mathrm{CuO}$ and then from $\mathrm{Cu}_{2} \mathrm{O}$ to $\mathrm{CuO}$. 

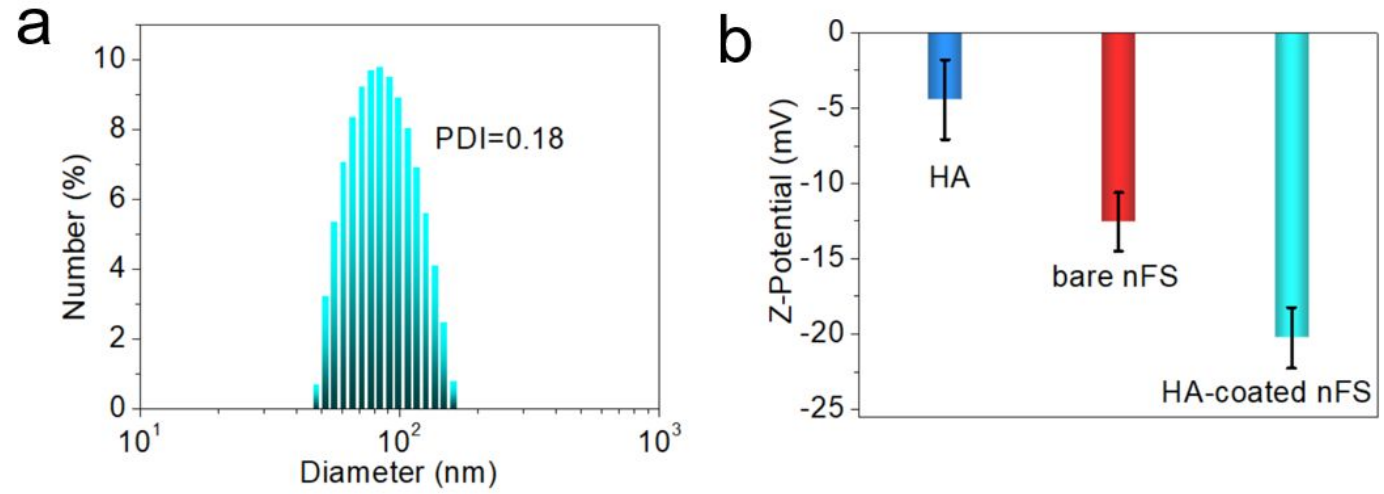

Figure S6. (a) The hydrodynamic diameter of HA-modified $\mathrm{nFs}$ in saline solution with the polydispersity index (PDI) as 0.18 . (b) The zeta potentials of HA, $n F s$, and HA-modified $\mathrm{nFs}$.
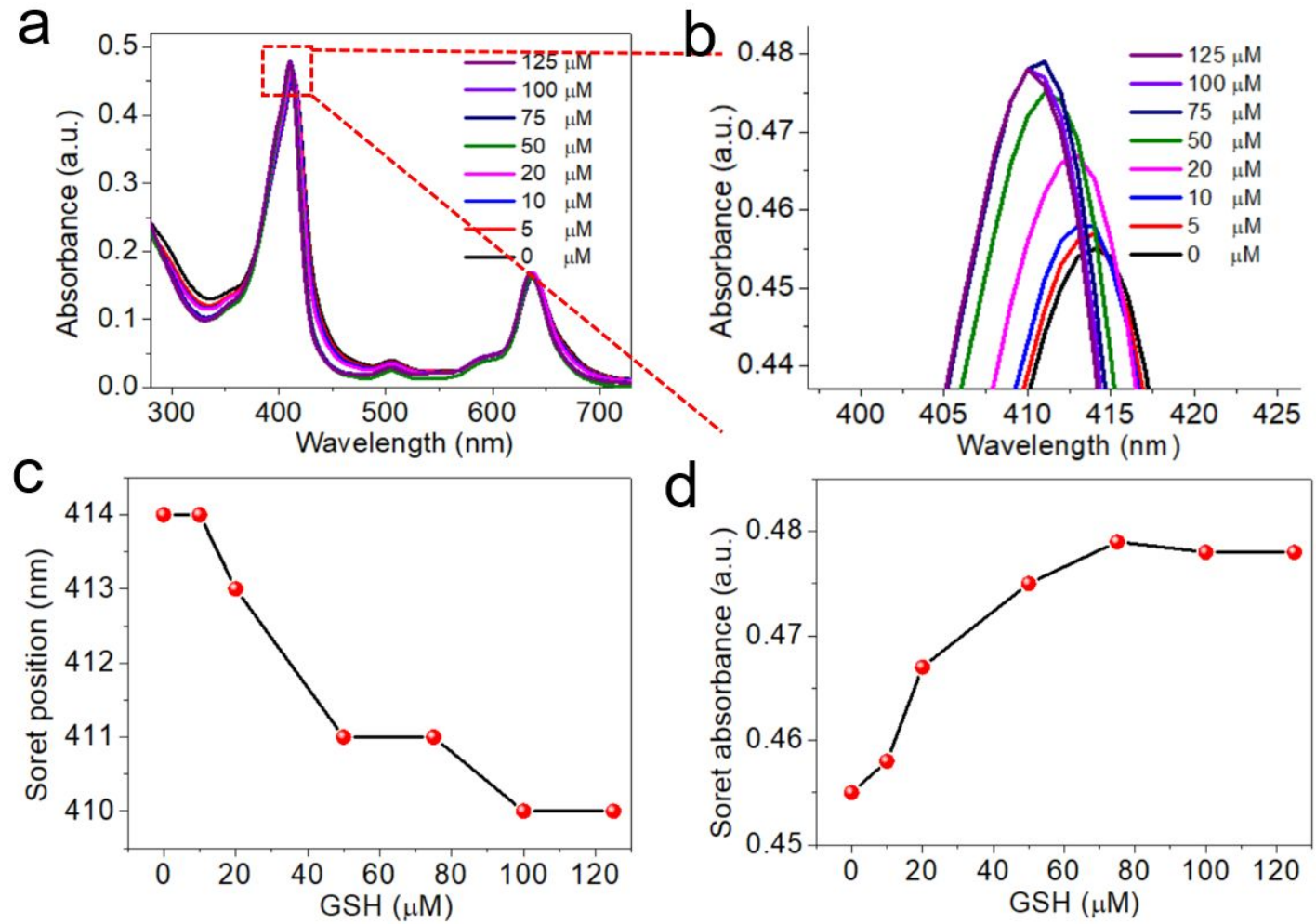

Figure S7. $(a, b)$ The photoabsorption spectra of $n F s+G S H$ with a series concentration of GSH up to $125 \mu \mathrm{M}$. (c) The changes in Soret band position and (d) absorbance versus GSH concentration. 

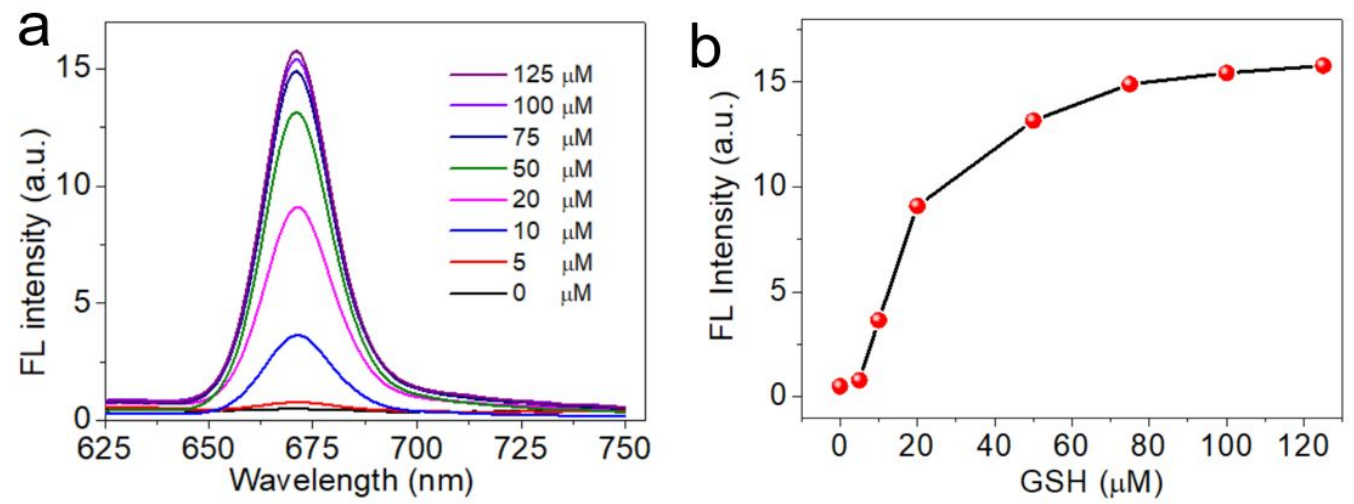

Figure S8. (a) The fluorescence band of $\mathrm{nFs}+\mathrm{GSH}$ with a series concentration of GSH up to 125 $\mu \mathrm{M}$. (b) The change in fluorescence intensity versus GSH concentration.

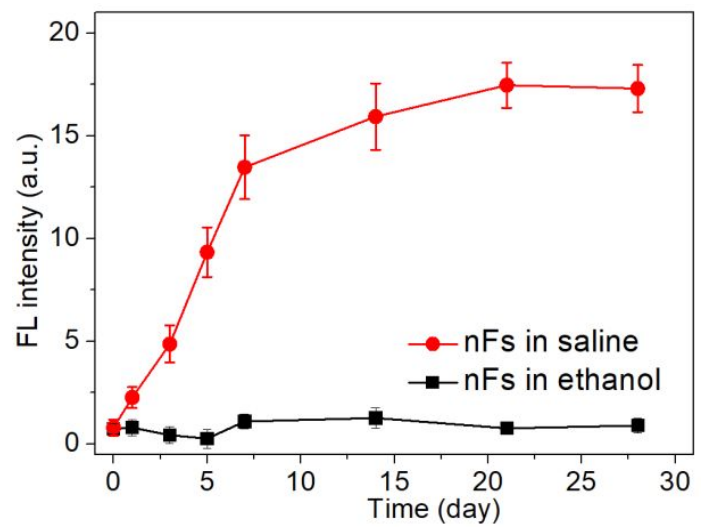

Figure S9. Changes in fluorescence intensity of $\mathrm{nFs}$ in ethanol and saline solution. The enhancement in FL intensity indicates the dissociation of $\mathrm{nFs}$.
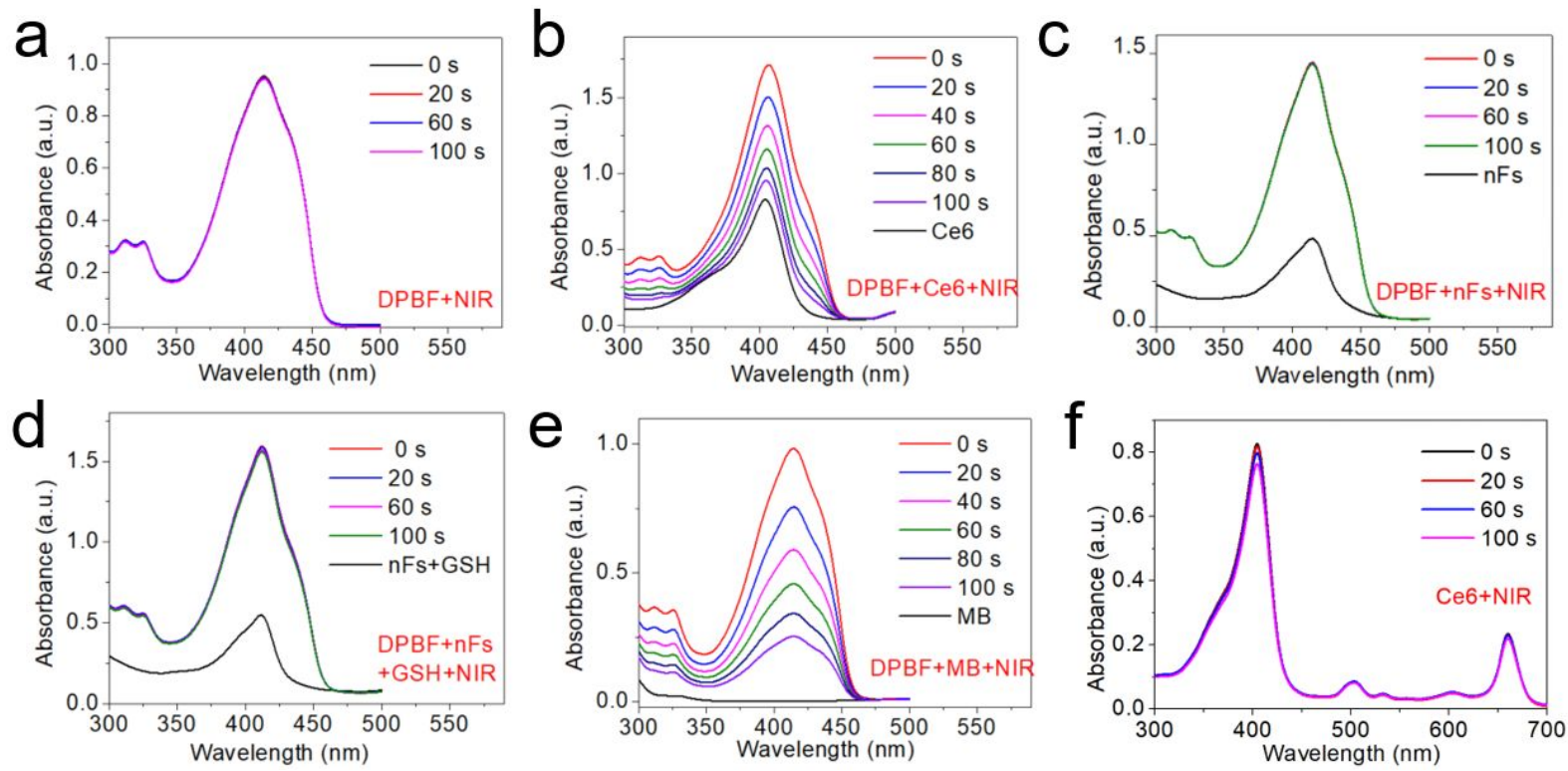

Figure S10. The photoabsorption spectra of (a) DPBF, (b) DPBF+Ce6, (c) DPBF+nFs, (d) $\mathrm{DPBF}+\mathrm{nFs}+\mathrm{GSH},(\mathrm{e}) \mathrm{DPBF}+\mathrm{MB}$, and (f) pure Ce6 $(5 \mu \mathrm{M})$ upon NIR irradiation. 
Table S1. The parameters of degradation rates of DPBF by Ce6, nFs, $\mathrm{nFs}+\mathrm{GSH}$, and MB.

\begin{tabular}{|l|r|r|r|r|}
\hline Equation & $y=a+b^{*} x$ & & & \\
\hline Weight & No Weighting & & & \\
\hline $\begin{array}{l}\text { Residual Sum } \\
\text { of Squares }\end{array}$ & 0.00626 & $1.1594 \mathrm{E}-5$ & $6.35603 \mathrm{E}-7$ & 0.00604 \\
\hline Pearson's r & -0.99418 & -0.91867 & -0.99964 & -0.99291 \\
\hline Adj. R-Square & 0.9855 & 0.80495 & 0.9991 & 0.98235 \\
\hline & & Value & Standard Error & \\
\hline Ce6 & Intercept & 0.95317 & 0.02863 & \\
\hline Ce6 & Slope & -0.00873 & $4.72816 \mathrm{E}-4$ & \\
\hline nFs & Intercept & 0.99783 & 0.00123 & \\
\hline nFs & Slope & $-9.46466 \mathrm{E}-5$ & $2.03488 \mathrm{E}-5$ & \\
\hline nFs+GSH & Intercept & 1.00005 & $2.88502 \mathrm{E}-4$ & \\
\hline nFs+GSH & Slope & $-3.55447 \mathrm{E}-4$ & $4.76446 \mathrm{E}-6$ & \\
\hline MB & Intercept & 0.94942 & 0.02814 & \\
\hline MB & Slope & -0.00776 & $4.64637 \mathrm{E}-4$ & \\
\hline
\end{tabular}
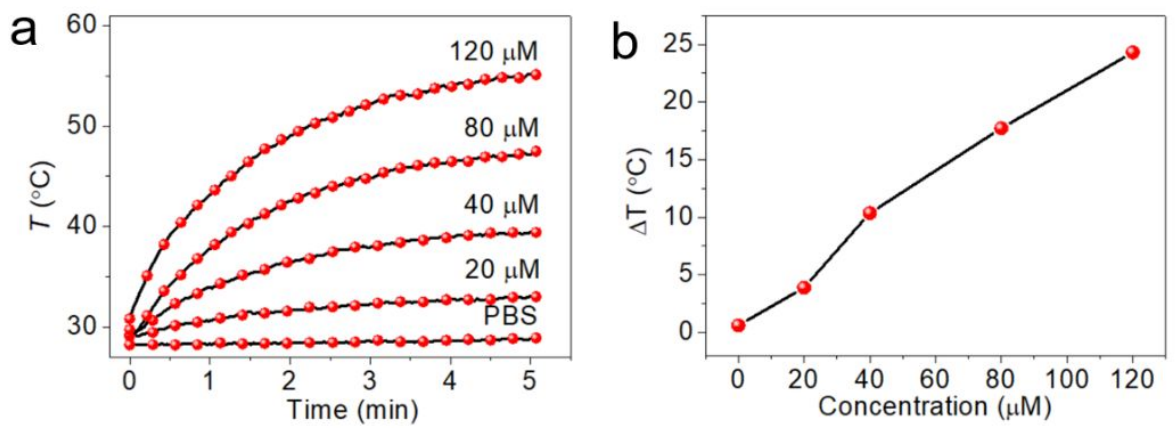

Figure S11. (a) The temperature curves of $\mathrm{nFs}$ solutions upon NIR irradiation $(660 \mathrm{~nm}, 0.5 \mathrm{~W}$ $\left.\mathrm{cm}^{-2}\right)$. (b) The temperature elevations $(\Delta T)$ versus concentrations of $\mathrm{nFs}$.
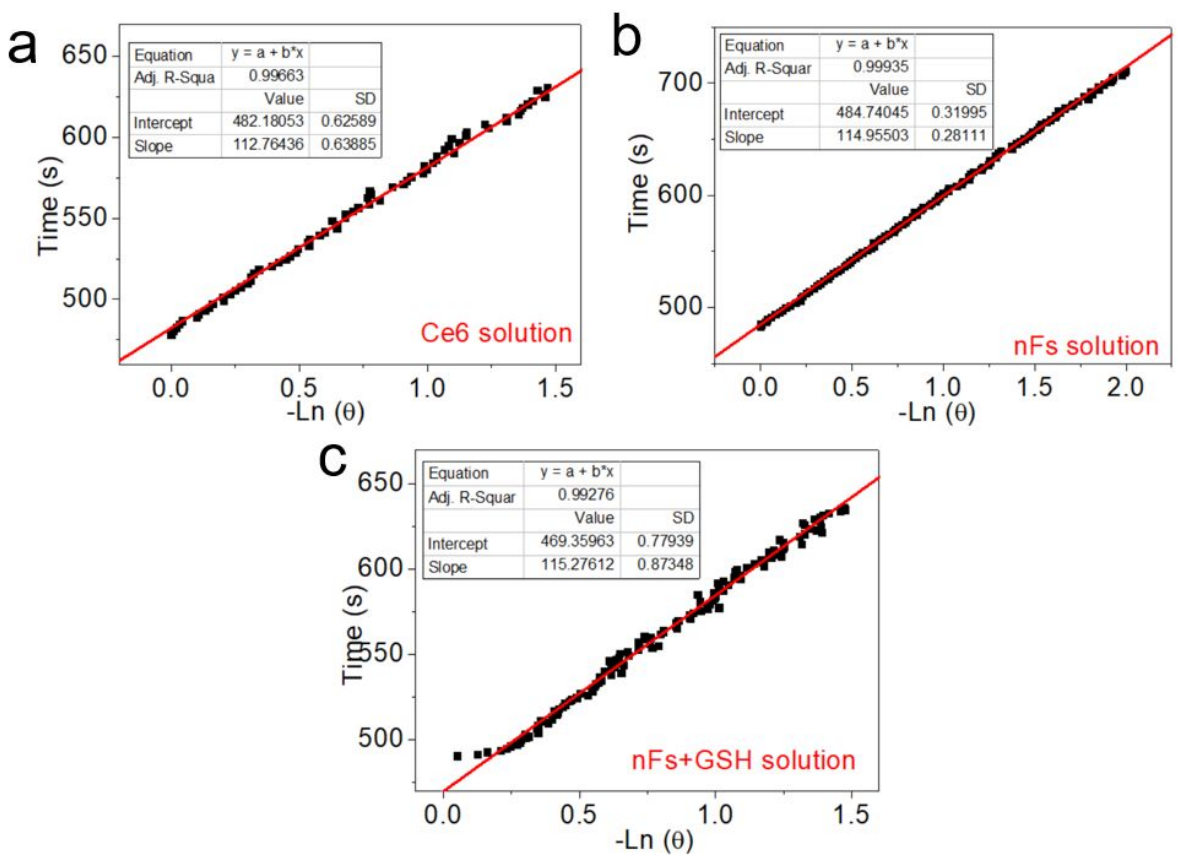

Figure S12. The system time constants obtained by linearly fitting time data versus $\ln (\theta)$ from the cooling period of NIR laser off, where $\theta$ is $\left(T-T_{\text {sur }}\right) /\left(T_{\max }-T_{\text {sur }}\right)$. 
Table S2. The detail parameters for the calculation of $\eta_{\mathrm{T}}$.

\begin{tabular}{ccccccc}
\hline Samples & $\Delta T_{\max , \mathrm{dis}}-\Delta T_{\max , \mathrm{H} 2 \mathrm{O}}\left({ }^{\circ} \mathrm{C}\right)$ & $A_{660}$ & $I(\mathrm{~mW})$ & $\tau_{s}(\mathrm{~s})$ & $h A$ & $\eta$ \\
\hline $\mathrm{Ce} 6$ & 6.5 & 0.756 & 200 & 112.76 & 3.72 & $14.7 \%$ \\
$\mathrm{nFs}$ & 19.4 & 0.520 & 200 & 114.96 & 3.65 & $50.7 \%$ \\
$\mathrm{nFs}+\mathrm{GSH}$ & 4.9 & 0.580 & 200 & 115.28 & 3.64 & $12.1 \%$ \\
\hline
\end{tabular}

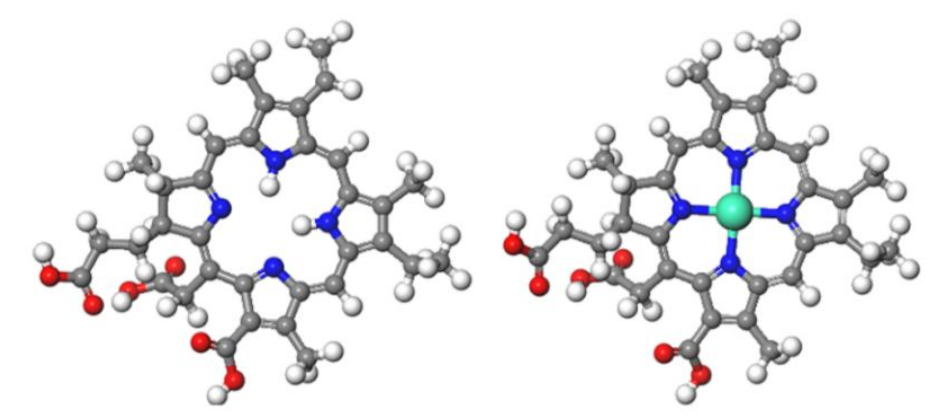

Figure S13. The computational structure of $\mathrm{Ce} 6$ and $\mathrm{CuCe} 6$.

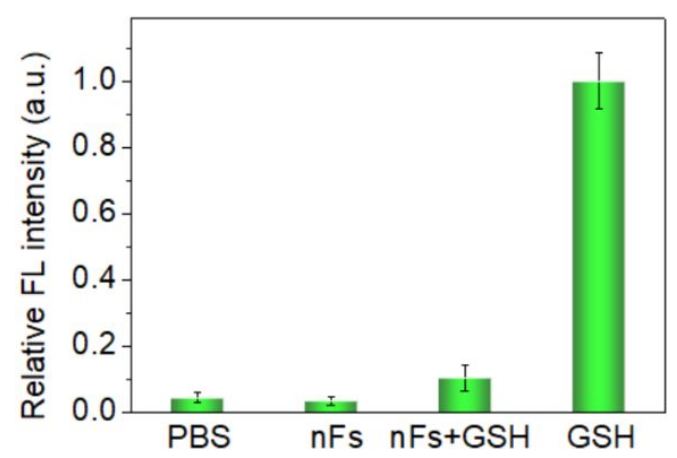

Figure S14. The relative fluorescence intensity of saline, $\mathrm{nFs}, \mathrm{nFs}+\mathrm{GSH}$, and pure GSH with the addition of Thiol Green assay, which was read by a fluorescence microplate reader at Ex/Em = $490 / 520 \mathrm{~nm}$.

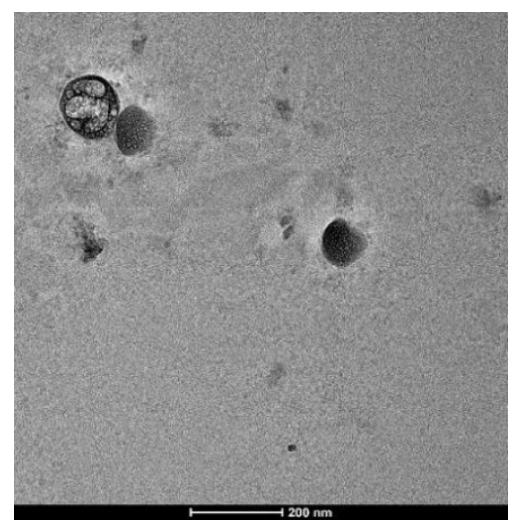

Figure S15. TEM image of nFs+GSH solution. 

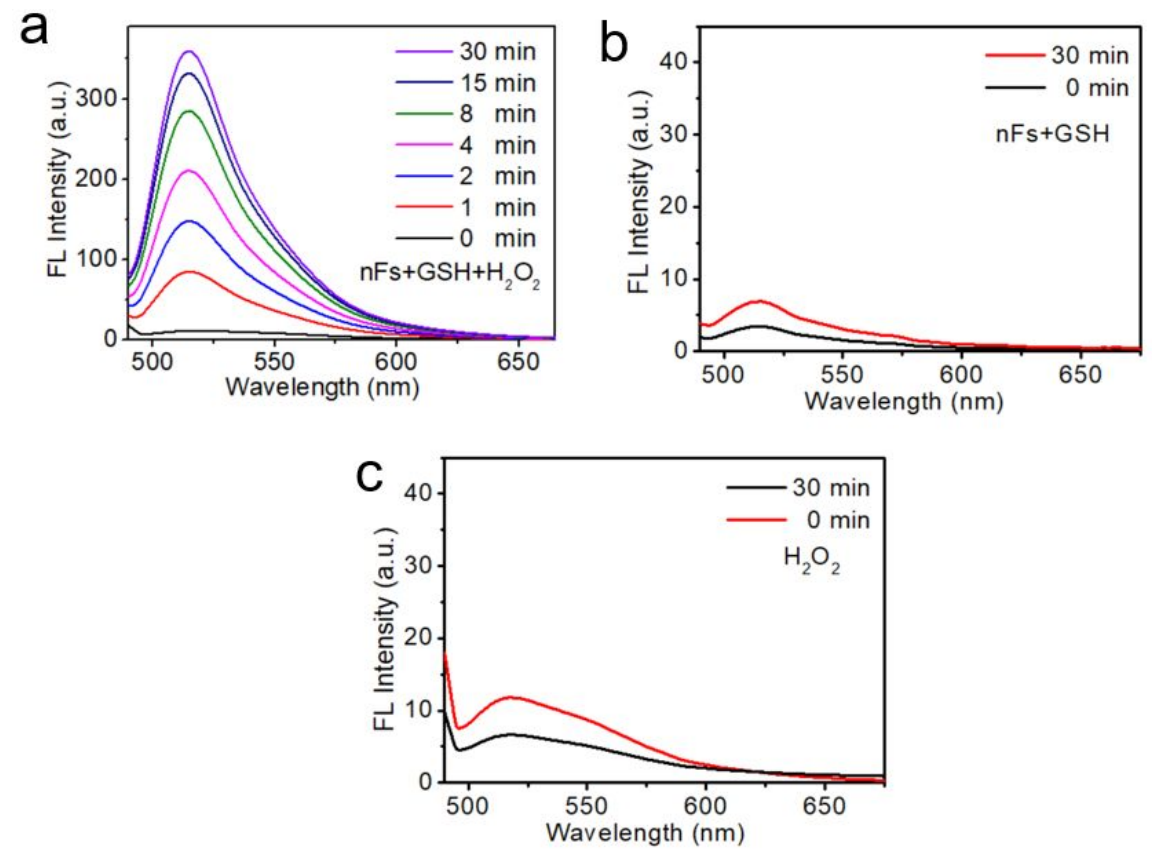

Figure S16. The time-dependent fluorescence spectra of APF treated with $\mathrm{nFs}+\mathrm{GSH}+\mathrm{H}_{2} \mathrm{O}_{2}$, $\mathrm{nFs}+\mathrm{GSH}$, and $\mathrm{H}_{2} \mathrm{O}_{2}$ respectively.
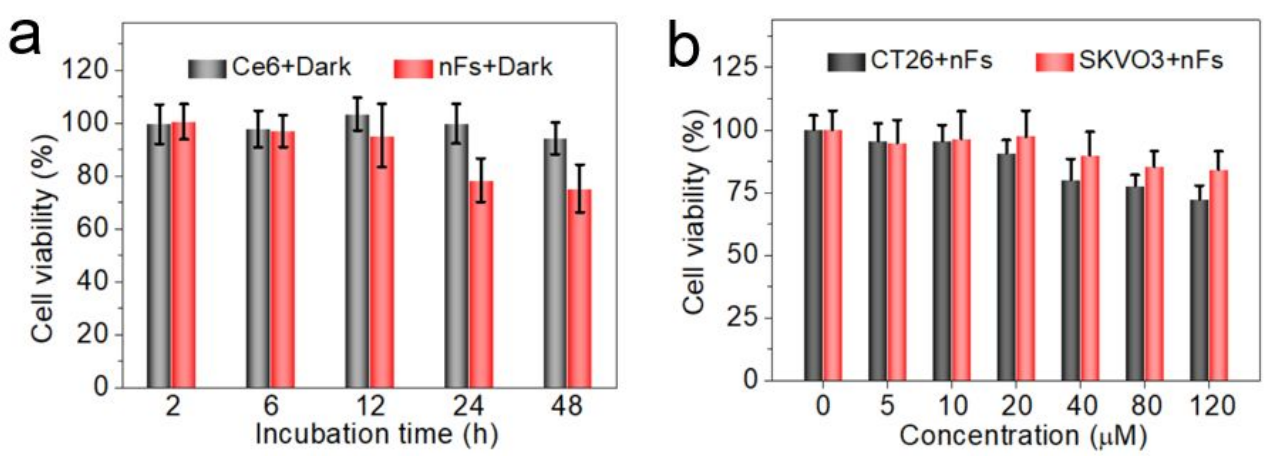

Figure S17. (a) The viability of HUVEC cultured with Ce6 or $\mathrm{nFs}$ for different durations in dark. (b) The viability of CT26/SKVO3 cells incubated with a series of concentrations of nFs for $48 \mathrm{~h}$.
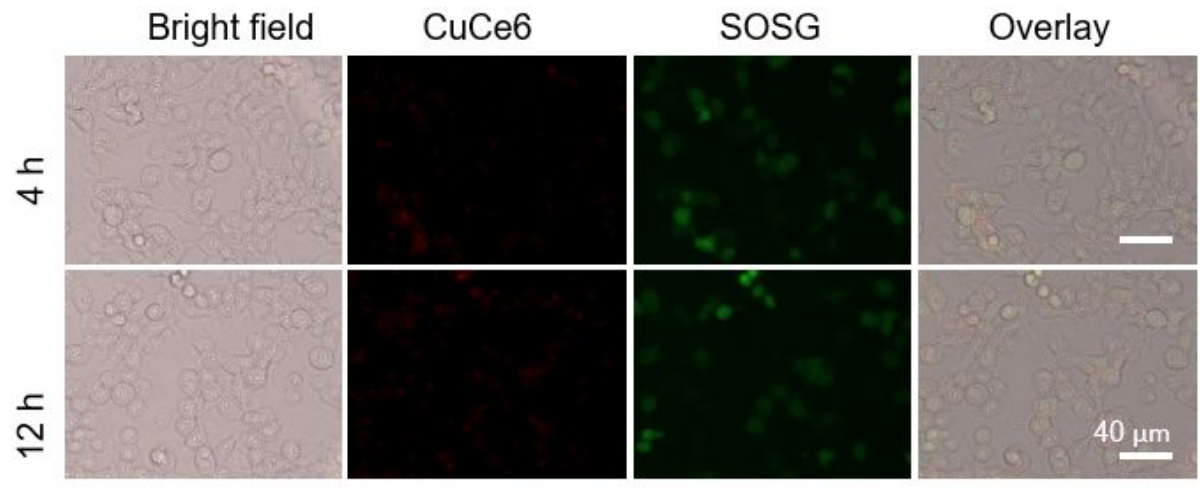

Figure S18. The fluorescent and bright field images of CT26 cells treated with $\mathrm{nFs}(80 \mu \mathrm{M})$ for 4 and $12 \mathrm{~h}$ and sunlight for $30 \mathrm{~min}$. 

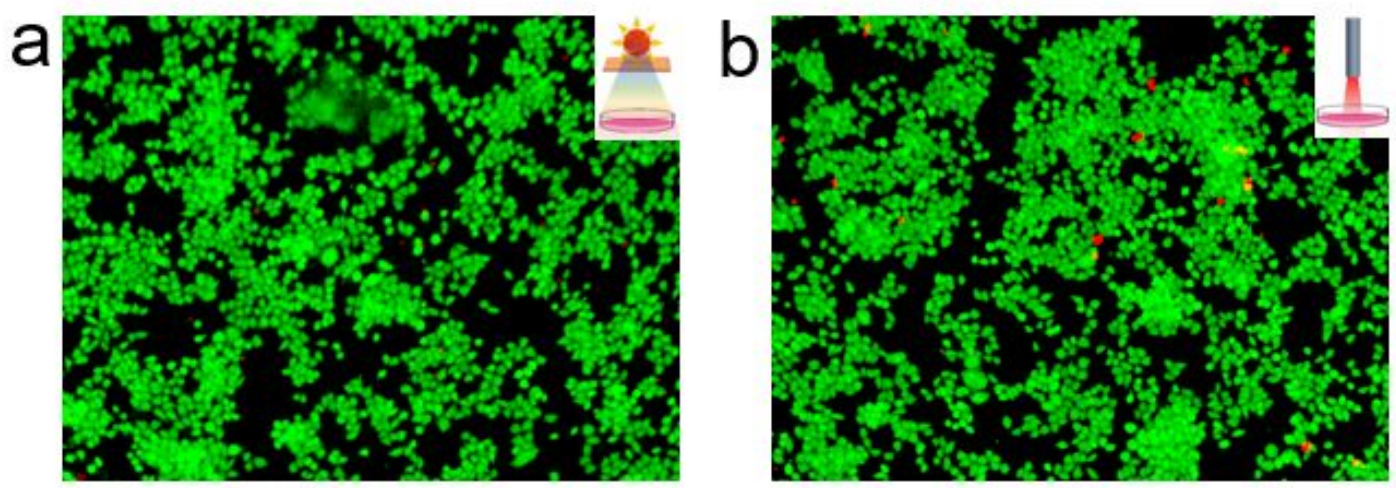

Figure S19. The fluorescent images of Calcein-AM-stained CT26 cells illuminated by (a) the simulated sunlight for $30 \mathrm{~min}$ or (b) NIR light $\left(660 \mathrm{~nm}, 0.5 \mathrm{~W} \mathrm{~cm}^{-2}\right)$ for $8 \mathrm{~min}$.

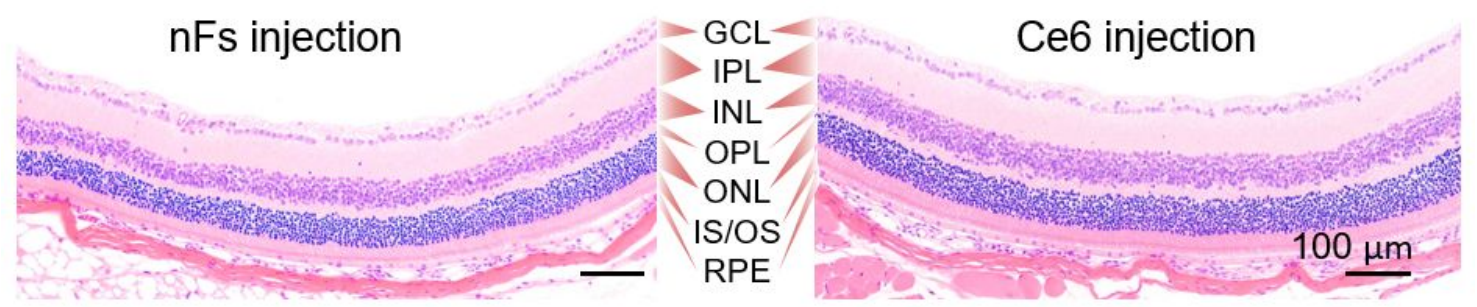

Figure S20. The images of H\&E-stained retina slices from Ce6/nFs-injected mice.
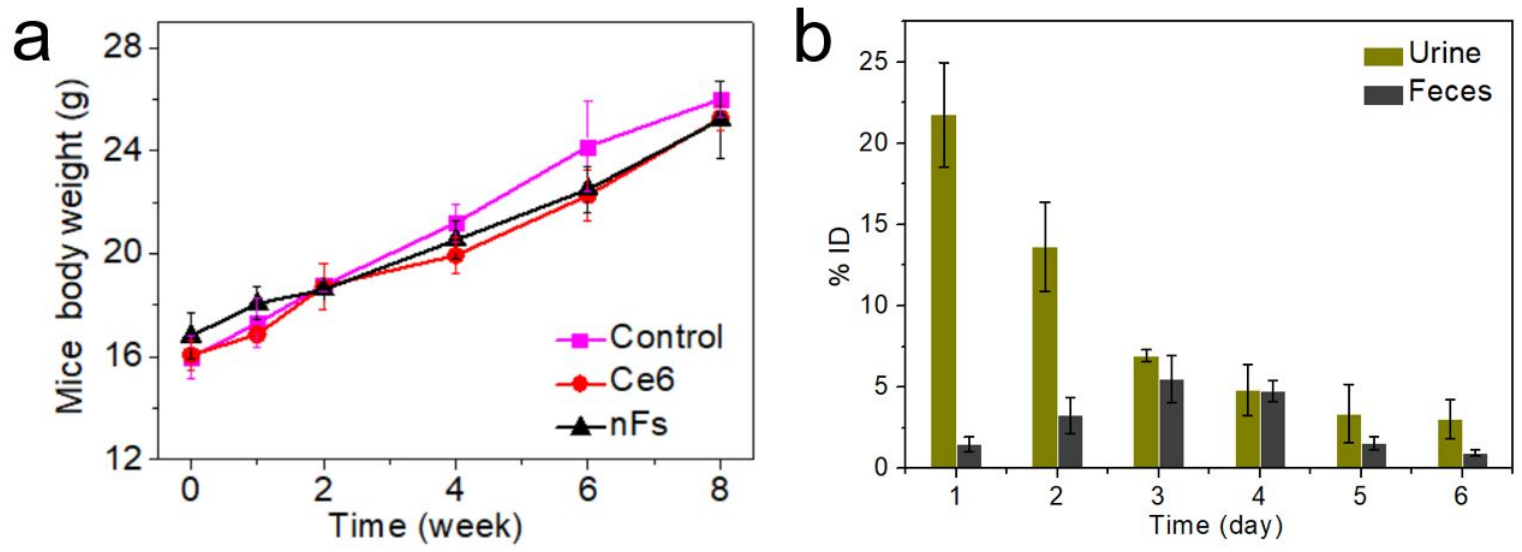

Figure S21. (a) The body weight of mice treated with Ce6 or nFs over a period of 8 weeks. (b) Time-dependent excretion of Hf in health mice after i.v. injection of $\mathrm{nFs}$. 
Table S3. The typical haematological indexes: white blood cells (WBC), red blood cells (WBC), hemoglobin (HGB), hematocrit (HCT), mean corpuscular volume (MCV), mean corpuscular hemoglobin $(\mathrm{MCH})$, mean corpuscular hemoglobin concentration (MCHC), and platelets (PLT).

\begin{tabular}{lllllllll}
\hline & $\begin{array}{l}\text { WBC } \\
\left(10^{9} / \mathrm{L}\right)\end{array}$ & $\begin{array}{l}\mathrm{RBC} \\
\left(10^{12} / \mathrm{L}\right)\end{array}$ & $\begin{array}{l}\mathrm{HGB} \\
(\mathrm{G} / \mathrm{L})\end{array}$ & $\begin{array}{l}\mathrm{HCT} \\
(\%)\end{array}$ & $\begin{array}{l}\mathrm{MCV} \\
(\mathrm{fL})\end{array}$ & $\begin{array}{l}\mathrm{MCH} \\
(\mathrm{pg})\end{array}$ & $\begin{array}{l}\text { MCHC } \\
(\mathrm{g} / \mathrm{L})\end{array}$ & $\begin{array}{l}\text { PLT } \\
\left(10^{9} / \mathrm{L}\right)\end{array}$ \\
\hline Control & $7.6 \pm 0.5$ & $10.2 \pm 0.4$ & $166 \pm 12$ & $62.8 \pm 5.4$ & $55.6 \pm 4.6$ & $14.2 \pm 2.3$ & $335 \pm 25$ & $890 \pm 35$ \\
$\mathrm{Ce} 6$ & $8.8 \pm 1.6$ & $9.8 \pm 1.7$ & $152 \pm 24$ & $70.5 \pm 8.8$ & $60.8 \pm 8.7$ & $15.0 \pm 1.7$ & $324 \pm 29$ & $980 \pm 46$ \\
$\mathrm{nFs}$ & $9.2 \pm 1.4$ & $10.8 \pm 0.5$ & $165 \pm 18$ & $68.2 \pm 7.6$ & $64.5 \pm 4.7$ & $14.9 \pm 4.2$ & $308 \pm 40$ & $920 \pm 44$ \\
\hline
\end{tabular}
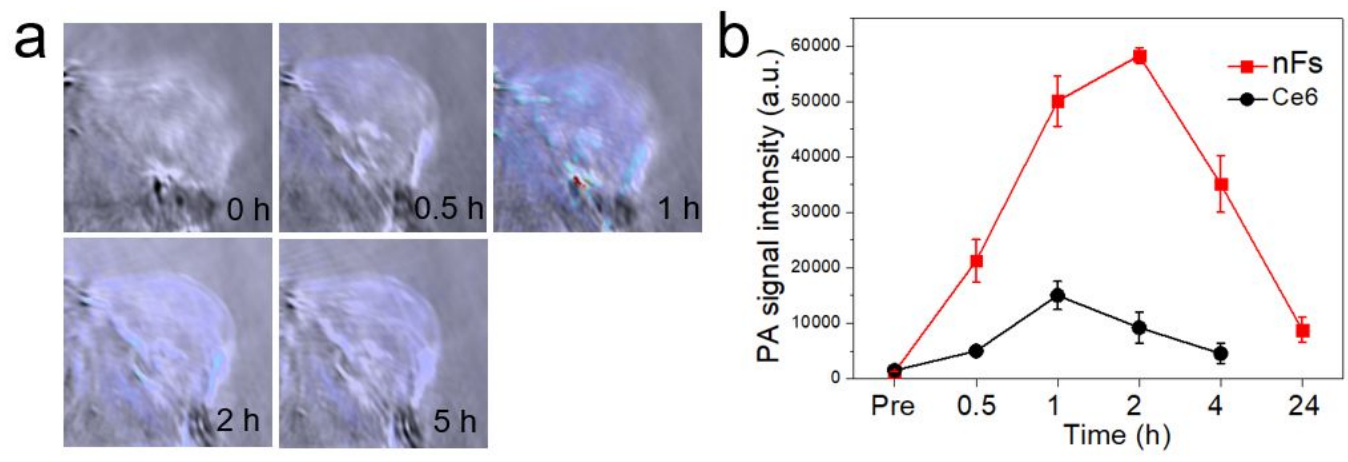

Figure S22. (a) The photoacoustic images of tumors of mice treated with Ce6 at the same concentration $(150 \mu \mathrm{L}, 2 \mathrm{mM})$. the red circles indicate the tumor area. (b) The time-dependent photoacoustic intensities of tumors.

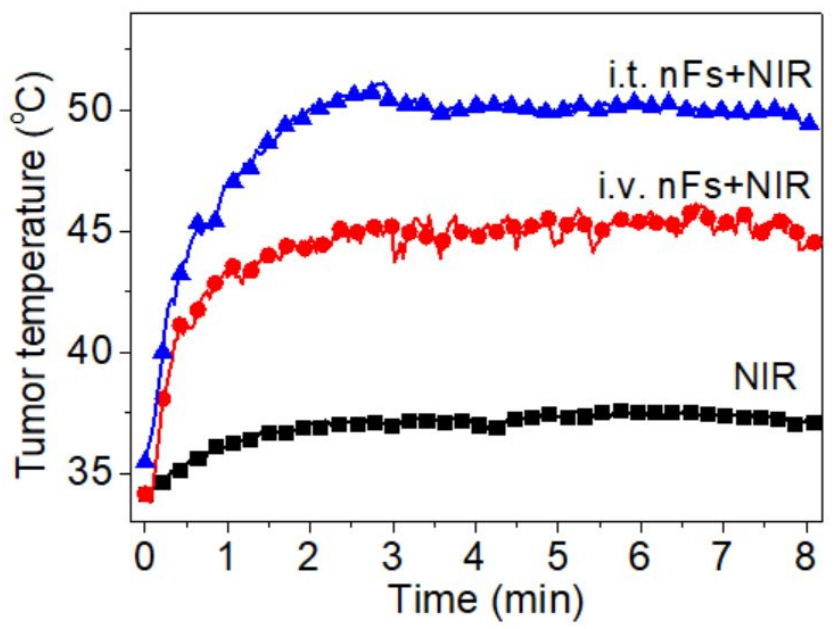

Figure S23. The temperature curves of tumors with NIR $\left(660 \mathrm{~nm}, 0.5 \mathrm{~W} \mathrm{~cm}^{-2}\right)$. 


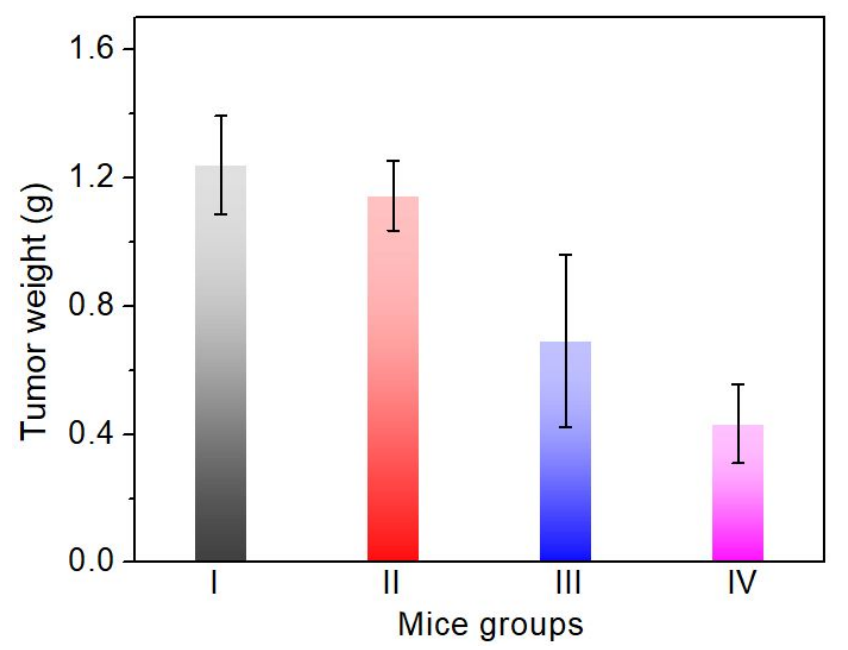

Figure S24. The average weight of extracted tumors in group (I-IV) on the 14th day.

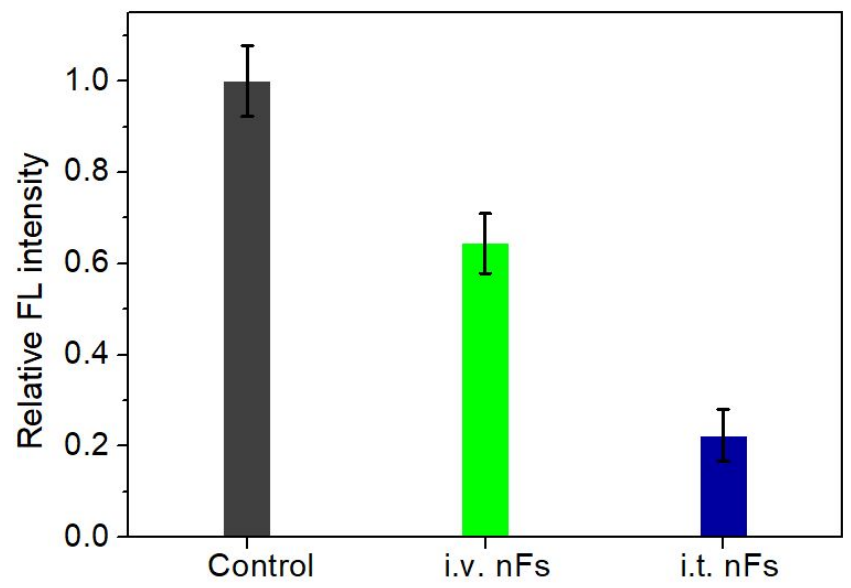

Figure S25. The relative fluorescent intensity of Thiol Green assay of tumor slices. 